\title{
Flexibility of Iranian Teachers Teaching Methods and High School Students' Gains
}

\author{
Mehdi Mohammadi ${ }^{1}$, Naeimeh Ahmadipour ${ }^{2}$, Reza Norouzi Kouhdasht ${ }^{3} \&$ Najmeh Bordbar ${ }^{4}$ \\ ${ }^{1}$ Associate Professor, Educational Administration, Faculty of Education and Psychology, University of Shiraz, \\ Shiraz, Iran \\ ${ }^{2}$ MA. Educational Administration, University of Shiraz International Unit, Shiraz, Iran \\ ${ }^{3}$ Ph.D. Student, Educational Administration, Faculty of Education and Psychology, University of Shiraz, \\ International Unit, Shiraz, Iran \\ ${ }^{4}$ MA. Student, Educational Administration, University of Shiraz International Unit, Shiraz, Iran \\ Correspondence: Reza Norouzi Kouhdasht, Educational Administration, Faculty of Education and Psychology, \\ University of Shiraz, International Unit, Shiraz, Iran. E-mail: r.norouzi20@yahoo.com
}

Received: March 27, 2016

Accepted: April 8, 2016

Online Published: June 20, 2016

doi:10.5539/mas.v10n10p48

URL: http://dx.doi.org/10.5539/mas.v10n10p48

\begin{abstract}
The teaching skills are the key element for all teachers. The main objective of this descriptive study was to investigate the relationship between Flexibility of Iranian Teachers Teaching Methods and High school Students' emotional, social and intellectual gains as a model. The study population included all Shiraz high schools teachers and their students. By stratified random sampling, 100 teachers and for each of them, 4 students were selected. Data instruments were flexible personal style questionnaires (Taggart \& Hausladen, 1993) and students gains subscale of college student experiences questionnaire (Kuh \& pace, 2002). After measurement of validity and reliability of instruments, they were distributed among sample and data was collected. Data was analyzed by inferential statistical methods included Pearson correlation coefficient and multiple regression. The results showed that: 1 . There is a relationship between teachers' intuitive and logical teaching style and student gains. 2 . The intuitive teaching style of teachers is stronger predictor of student gains.
\end{abstract}

\section{Introduction}

Education is an activity that leads to the creation and development of some features and circumstances of physical, intellectual and moral that in general political community and the specific environment of child expect from them. In this regard, teacher and his responsibilities plays a key role in this developed process that the teaching is the main task and one of the criteria of his competence. Teaching is the process that teacher creates in favorable conditions and provides process of training and learning to the students (Kennedy, Alton\& Lee 2006). They believed that teaching is a complex process and it designed before the teacher acts .Its aim is to challenge teacher with learning process so it as a carrier influences on how the activity goes on the class .It is essential for the teacher knows what happens in the teaching process (Kachk \& Eagan, 2003). Teacher's teaching style, is an important element in the teaching-learning process (Hmlych, 2002 \& Heredia, 1999). Academic success depends not only on students' learning styles, but also teaching styles play a significant role in this process (Uzuntiryaki, 2007). Teaching style reflects the quality of teacher behaviors that applies in the classroom (Grasha, 1996). In other words, teaching style refers to behaviors that teachers show in their dealings with students and it plays an important role in different aspects of teaching (Hmlych, 2002). Therefore leadership the educational process and its impact on students and their learning ability known as teaching style. (Grasha, 1996). In relation to the importance of teaching styles, there are several views about it. Teacher's teaching style is an important element in the teaching-learning process (Hmlych, $2002 \&$ Heredia, 1999). Academic success depends not only on students' learning styles, but also teaching styles play a significant role in this process (Uzuntiryaki, 2007). Teaching style reflects the quality of teacher behaviors that applies in the classroom (Grasha, 1996). In other words, teaching style refers to behaviors that teachers show in their dealings with students and it plays an important role in different aspects of teaching (Hmlych, 2002).Therefore leadership the educational process and its impact on students and their learning ability known as teaching style (Grasha, 1996). In relation to the importance of teaching styles, there are several views. Among them Don (1990) emphasized on this point that a 
good teaching depends on teacher knowledge of teaching styles. Knowledge of teaching styles, learning styles and teaching styles accordance the diversity and flexibility in its application, has a considerable impact on learning and learners 'satisfaction and dynamic style of teaching and learning support students' satisfaction (Brown, 2003). But flexibility in teaching style, from the perspective of Lampert (2001), is the encouragement of the students to explain and justify his idea and the procedure to follow and anticipate the unexpected cases by students it may happen, the teacher is waiting to change the schedule. Teachers can participate more effectively in team work using adjustable practices. It is likelihood adjustable teachers and students select appropriate behaviors in the school environment. Perhaps the habit of relying on the behavior of the teachers with less flexibility regardless of further location. Instead, the lack of flexibility in learning negatives affects species and other factors such as attendance and discipline problems at school. According to McTaggart and Hasladn (1993) in the field of education, based on the findings of the researcher-analysis in the field of old, new theories and emerging styles of teaching and the flexibility of teachers in styles teaching related to it, they explained rationally the flexibility in two-categories of teaching style sensory-intuitive and flexibility of teaching style. Teachers easily adapt to change and have willingness to adapt their teaching style to learning style of students give them, they are interested in to solve new problems, they don't like to do repetitive tasks, they enjoy learning new skills more than utilization it, they follow work with energy and enthusiasm to do in primrose opportunities and short term, they repeatedly and quickly conclude the results. They are very patient in complex situations; they follow inspiration whether it's good or bad. They are addressing intuitive orientation before sensory learning style in the genre of students who taught them the flexibility to be compatible with the type of data retained information for longer use them more effectively and in the future they will have positive orientation about the subject in front of their peers who mismatch their learning teaching methods. Teachers who are relatively non-emotional and don't care about the feelings of the students, they may annoy students without any excuses, they like analyzing and putting things like rational order and harmony. They adopt decisions without personal desires and ignore students' willingness. If necessary they punish and expel students. They only come with students that are reasonably good-hearted and may seem ruthless and cruel, they take orientation to be logical. A successful teacher teaches coordinating with the principles of teaching styles and learning styles to help students gain maximum learning and to develop their academic achievements (Hmlych, 2002).

One academic achievement of the students and teachers teaching style that these achievements are the index to improve the performance of teachers and their success. Characteristics of outcome-based education includes the creation of complete defined learning outcomes and writing achievements obtained in the course curriculum design, learning strategies and learning opportunities to ensure the achievement of results, achievements and evaluated according to the evaluation process for students to ensure the achievements, providing Intermediaries and enrich students' learning as much as is appropriate (Harden, 2002).The role of academic achievements of students is a good criteria and an appropriate understanding of important educational goals in the macro level respectively. Achievements are generally divided into two categories: knowledge and attitude. knowledge achievements includes increasing specialized knowledge in the field of science and technical courses which can be obtained by evaluation of the curriculum and its overview achievements includes the growth and development of students' attitude, demographic, social, ethical, critical (Paskarla and Trnzyny, 1991). Scientists have different views on the extent and variety of the academic achievements of students in different decades. Austin (1973, 1993 \& 1984) studied student achievement in three dimensions to consider division achievements: the type of outcome (mental and behavioral), data type (mental and emotional) and the time spending on learning (Austin, 1984, Paskarla and Trnzyny, 1991). Austin (1984) emphasized more on the "time". He believes that one of the most important aspects that affect student achievement is the time they spend for education. Certainly among the students who engaged in short-term with students who are under-educated, different results obtained. Stein presented a conceptual framework for the achievement of students i.e. input model, output environment .The purpose of stein about input is personal characteristics of students enter the campus. The intended purpose of the campus is various academic programs, educational policies, educational resources, teachers, friends and classmates, interactions and overall experiences gained in the educational process and the purpose of output is growth and all-round development of students after graduation in the environment (Austin, 1993). Also, Hunter et al., (2007) concluded with extensive research that the academic achievements have been divided into six categories: 1) personal and career achievement like achievements in self-esteem and academic relationships with faculty members and peers. 2) Intellectual achievements, including the application of their knowledge and critical thinking skills to do their research, and extending their knowledge and understanding of communication among the various sciences. 3) Career socialization achievements, such as changes in attitudes and behaviors of students who indicates the career norms. 4) The achievements of different skills including communication skills, technical skills and working with computer skills and more. 5) Increasing preparedness to 
graduate in a period of time and transmit to higher education and enter into work environment. 6) Transparency achievements remain and edit in their jobs. Endo and Harpl (1982) classify achievements to 4 items :personal / community achievements to care about self-directed leader learning, the importance of independence, social confidence, public participation in extracurricular activities and good social experiences, intellectual gains in the sense of having adequate knowledge, adequate math skills, development of problem-solving skills, development of public speaking skills, progress towards the intellectual, cultural activities and obtaining the highest degree of participation in planning, achievement in this sense that the personal learned will be according to his ability and his potential, and not be the distance between the potential and actual student and at last academic satisfaction. And the same research Tom (2004) concluded that the achievements of students have four dimensions: career, personal, educational and rational achievement .1career achievement: gaining knowledge and skills in various fields, to obtain information and knowledge and to experience in various general fields and scientific knowledge and the ability to use modern technology such as computers, the Internet and ... . .2- Personal achievement :includes understanding your strengths and interests and attitudes, sense of independence and confidence in the social environment, get familiar with internal values and ethical standards, the ability of knowing about the family and the people in community, communication skills to interact with people in society, sense about social commitment and the ability to meet his/her responsibilities. Personal achievement reflects a change in personal growth, including the growth of confidence and independence in practice (Aynarsvn and Klarkbrg, 2010). 3. Educational achievement: the spirit of partnership and teamwork, the ability to create an international perspective to all cultures, transparent and effective writing skills interested in, awareness of the philosophies and different cultures, the ability to adapt to changes, the ability to identify and to connect with cultures similar to their own culture as well as good ability to communicate with different cultures with their own culture. 4- intellectual achievement: The ability to solve logical problems and analytical skills, the ability to criticize and examine the phenomena around to read or to content, The ability to recognize similarities and differences between different ideas, and the ability to understand the principles of his /her faith and to expand them and to accept different views and different ideas (Tom, 2004). Intellectual achievement reflects estimated changes in mental and general abilities of the students. For example, analytical and logical thinking, combining and integrating ideas and information (Einarson \& Clarkberg, 2010).

In such circumstances, it seems to be coordinated with the strategic learning, teaching styles and selected teaching methods to do good and to guide, to widespread and to lead the student. therefore it consists of three feature: interaction or relationship between teacher and student, teacher and existence of purposeful activity resilience in teachers teaching to change student behavior, or in other words, changes in concepts of different attitudes, attitudes, beliefs, habits and kinds of behavior developmental psychology (emotional development, intellectual and social) and psychological or general types of changes that we want to create in students. In this regard the teacher is required to use flexible teaching styles.

Because of the importance role and the status of flexibility in methodology and teaching styles as the main principles in all aspects of inclusive growth on one hand and the lack of a comprehensive model for guiding the two in line with each other to accomplish this, it is necessary to check the status of flexible teaching styles and it is essential among the necessities component. The present study aims to investigate the relationship between flexible teaching styles of teachers and academic achievement in high school students. In this model, the variable is flexible teaching style as predictor variables i.e. two styles as intuitive and logical styles.

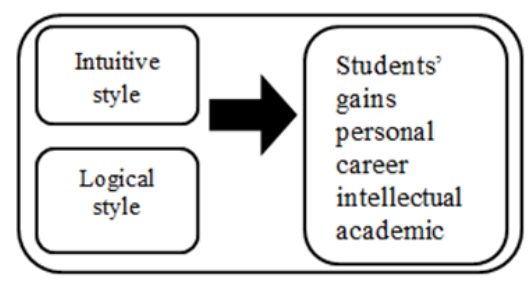

Figure 1. Conceptual model of students' gains

\subsection{Research Objectives}

1. the relationship between a types of teaching styles and academic gains of high school students in Shiraz. 
2. Predicating role of teachers' teaching styles flexibility for students' gains.

\subsection{Review of Literature}

Van Evera (2007) showed in a study entitled The role of feedback from active teaching in elementary-school students that there is a significant efficacy that enabled learning feedback from a significant increase in efficacy elementary students .Dogru \& Tekkaya (2008) studied the effectiveness of traditional teaching models and learning cycle to success of eighth grade students in the science of genetics and heredity. The analysis showed that there are significant differences between the control and experimental groups and experimental groups performed better in this area. The results also showed that the ability of logical thinking and meaningful learning the difference and change had an important contribution to the success of students. Fulton \& Sabatino (2008) studied on learning cycle model, they concluded that this model is very effective in understanding the relationship between mathematics and science, and students also motivated during lessons. Grasha (1996) believes that the dominant style of teaching faculty is career method and Smith \& et al (2009) also believes that teaching style based on knowledge is the dominant style of most teachers. Balcı, Çakıroğlu \& Tekkaya (2006), examined the traditional perception of the learning cycle training students in five and eight grades about the concepts of photosynthesis and respiration in plants. The results of this study showed that there is significant differences between experimental and control groups. Results revealed that students in the experimental group who trained using five learning cycle, they had a better performance in tests related to photosynthesis and respiration in plants than the control group. Research by Yalcin \& Bayrakceken (2010) showed that the cycle of learning lead to improve student learning. In this study, different classes of conventional and traditional methods compared by classes of learning cycle. The results showed that the learning cycle approach is more effective in comparison to traditional approaches, because most of the students participated in this procedure and students' interest in lessons and the subject of learning lessons increased their learning.

\section{Methods}

This study is the descriptive study. The population included all Iranian teachers and high school students in the four areas of the Shiraz city. By stratified sampling, 100 teachers were selected and by simple random sampling, for each teacher class, four students were selected (400 students). Study instruments included Personal Style Inventory (PSI)which involved 30 items and two sub-scales (intuition and logic) Likert-type. Validity and reliability of subscales. Intuitive validity was 0.64 and reliability 0.82 and logic subscale validity was 0.58 and reliability 0.80 , confirms the validity and reliability of the instrument. The subscale of students' gains from the CSEQ(kuh and Pace, 2002). This subscale consists of 19 items and 5 personal dimension, science and technology, public, career and cognitive skills, 5 choices of Likert type. Validity and reliability of subscale was calculated. Validity of career gains(0.71), personal gains $(0.65)$,academic gains $(0.65)$, intellectual gains $(0.64)$ and Cronbach's alpha of career gains $(0.86)$, personal gains $(0.84)$, academic gains $(0.81)$ and intellectual gains (0.79) confirms the validity and reliability of the instrument. Pearson correlation coefficient and multiple regression coefficients was used for data analysis.

\section{Results}

Is there a relationship between a types of teachers' Iranian teaching styles and students' gains? According to Table 1, there is a significant positive relationship between intuitive and logical teaching style and all aspects of students' gains.

Table 1. Correlation matrix between teaching styles and growth

\begin{tabular}{llllll}
\hline \multicolumn{2}{l}{ Students gains } & \multicolumn{3}{c}{ Covert Variable } \\
\hline academic & career & intellectual & personal & evident variable & Latent variable predictive \\
$0.81^{* *}$ & $0.78^{* *}$ & $0.45^{* *}$ & $* * 0.71$ & intuitive & Teaching methods \\
$0.48^{* *}$ & $0.52^{* *}$ & $0.67 * *$ & $* * 0.62$ & logical & \\
\hline
\end{tabular}

Does the Iranian teachers' intuitive and logical teaching styles predict high school students gains? To measure the power of Iranian teachers' intuitive and logical teaching styles for students' gains, multivariate regression analysis showed logical teaching style is a positive and significant prediction of personal growth ( $\beta$ $=0.22, \mathrm{p}<0.05)$, academic $(\beta=0.21, \mathrm{P}<0.05)$, Intellectual $(\beta=0.16, \mathrm{p}<0.05)$, career $(\beta=0.22, \mathrm{P}<0.05)$ and intuitive teaching style is a positive and significant prediction of personal growth $(\beta=0.42, \mathrm{p}<0.05)$, academic $(\beta$ 
$=0.59, \mathrm{P}<0.05)$, Intellectual $(\beta=0.72, \mathrm{p}<0.01)$, career $(\beta=0.22, \mathrm{P}<0.05)$. According to high degree of indexes NFI(0.98), NFI(0.97), NFI(0.98), NFI(0.95), SRMR(0.03) and low degree of RMSEA and SRMR(0.04). confirm the model fitness was confirmed approved.

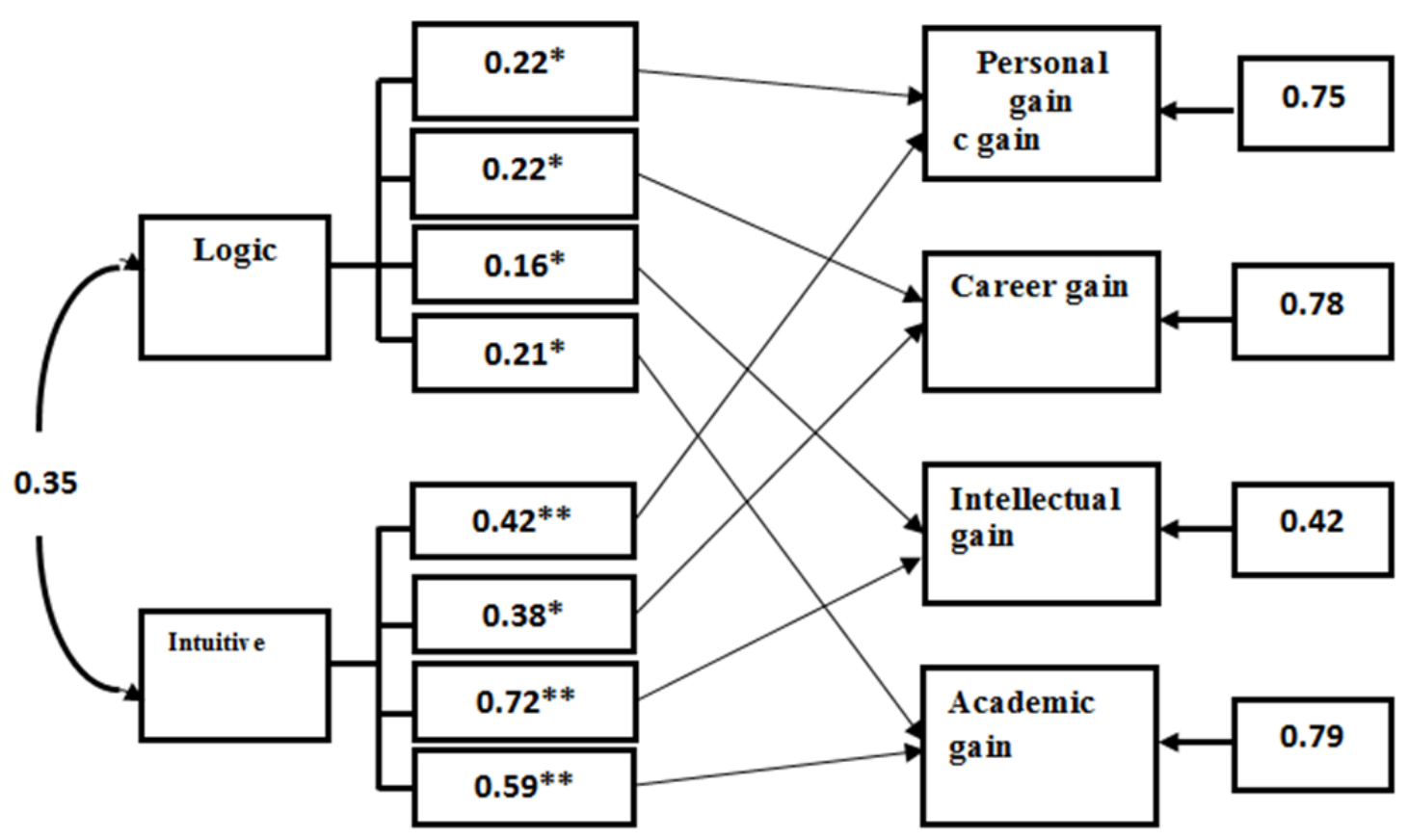

Figure 2. Review the power of intuitive and logical teaching style in predicting academic achievement of high school students in Shiraz

\section{Conclusions and Recommendations}

Assessment of the teaching style of most teachers in high school Shiraz city showed that most teaching style of them is the intuitive style. This means that team works are more favorable for teachers during teaching. They preferred to use Imaginative solutions and public opinion in order to get things done, and more general guidelines. Using this style of teachers in discovering the unknown by means of free association helped them to look at the problem as a whole and in all its dimensions. Teachers with Intuitive style fresh ideas consider students as a sign of their intelligence and they know new ideas and getting along with others the key factor in their success.

But the results evaluation of the gains of high school students reported somewhat successful our education in order to achieve personal and intellectual gains of students in pursuant to promote their capabilities to the values and moral standards, independence and confidences as well .Also development their social relationships with other people and increasing independent learning is the pursuit of their ideas and obtaining information. On the contrary, this organization doesn't have the ability to create an appropriate context for educational and career gains and it has failed, so that it couldn't even develop moderately learners to apply their knowledge and their practical skills for life, to obtain public information in different fields of science, the ability to cope with changes (new technology, job or personal circumstances and variety of analytical and problem solving skills.)

The outcome of the reviews about a variety of teaching styles and academic gains of students and the teaching styles of intuitive and logical in predicting academic gains of high school students in Shiraz shows that when teachers teach two methods of intuitive and rational to teach, they increase learners' gains. But obtained coefficients when they apply intuitive teaching style, according to this method, the students obtain higher gains. In other words, when the teacher uses intuitive method, the student will be able to write clearly and effectively and increases his ability to act as a member of a team. Also he can find by using this style strong sense of social responsibility, awareness of the philosophies, cultures and different ways of life, and he/she will be able to collect set of data associated with a business and see an international and inter-cultural perspectives and will be able to sum up their ideas, to pay attention to the communications, the similarities and differences between the ideas and to know the abilities, interests and its own personal characteristics. 
Motivation can be trained successfully. Students can learn to do a better safe task. By helping students and use an appropriate teaching style, to learn their strengths \& weakness to achieve their academic gains in the personal, social, career dimensions and training them in the bright future, we can help them to control their own behavior .perhaps this point expresses critical tasks of managers and directors of education as a way for teachers to choose their teaching style, and may be the Secretary through proper selection and modeling their teaching style help to change documental patterns of students and will have significant contribution to their progress.

\section{References}

Astin, A. (1973). The impact of dormitory living on students. Educational Record, 54(9), 204-210,

Astin, A. (1984). Student involvement: A developmental theory for higher education.

Astin, A. (1993). What Matters in College? Four Critical Years Revisited.

Balcl, S., Çakıroğlu, J., \& Tekkaya, C. (2006). Engagement, Exploration, Explanation, Extension, and Evaluation (5E) Learning Cycle and Conceptual Change Text as Learning Tools. Biochemistry and Molecular Biology Education, 34(3), 199-203. http://dx.doi.org/10.1002/bmb.2006.49403403199

Brown, B. L. (2011). Teaching Style vs. Learning Style. Retrieved from: http://www.calpro-online.org/eric/textonly/docgen.asp?tbl=mr\&ID=117

Doğru A. P., \& Tekkaya, C. (2008). Promoting Students' Learning in Genetics With the Learning Cycle. Journal of Experimental Education. 76 (3), 259-280. http://dx.doi.org/10.3200/JEXE.76.3.259-280.

Dunn, R., Deckinger, E., Withers, P., \& Katzenstein, H. (1990). Should college students be taught how to do homework? The effects of studying marketing through personal perceptual strengths. Illinois School Research and Development Journal, 26(3), 96-113.

Einarson, M. D., \& Clarkberg, M. E. (2010). Race differences in the impact of students' out-of class interactions with faculty. Journal of the Professoriate, 3(2), 101-136.

Endo, J. J., \& Harpel, R. L. (1982). The effect of student-faculty interaction on students'

Fulton, J. P., \& Sabatino, L. (2008). Using the scientific method to motivate biology students to study precalculus. Selden: Taylor and Francis Group, LLC.

Harden, R. M. (2002). Developments in outcome-based education. Medical Teacher, 24(2) 117 - 120. http://dx.doi.org/10.1080/01421590220120669

Heimlich, J. E., \& Norland, E. (2002). Teaching Style: Where Are We Now? New Directions for Adult and ContinuingEducation, (93), 17-26. http://dx.doi.org/10.1002/ace.46

Heredia, A. (1999). Cultural Learning Styles. 1999. Retrieved from http://library.educationworld.net/a12/a12-166.html

Hunter, A. B., Weston, T. J., Laursen, S. L., \& Thiry, H. (2009). URSSA: Evaluating Student Gains from Undergraduate Research in the Sciences. University of Colorado, Boulder. Council on undergraduate Research, spring, 29(3), 15-19.

Kauchak, D. P., \& Eggen, P. D. (2003). Learning and teaching: Research-Based Methods. Boston: Allyn and Bacon.

Kennedy, M. M. (2006). Knowledge and vision in teaching. Journal of Teacher Education, 57(3), 205-211. http://dx.doi.org/10.1177/0022487105285639

Lampert, M. (2001). Teaching problems and the problems of teaching. New Haven, CT: Yale University Press.

Lee, A. A. (2006). How teaching influences learning: Implications for educational researchers, teachers, teacher educators and policy makers. Journal of Teaching and Teacher Education, 22, 612-626. http://dx.doi.org/10.1016/j.tate.2006.01.002

Pace, R., \& Kuh, G. (2002). College student experiences questionnaire. India University. Retrieved from www.indiana.edu/ cseq/qualeff.html

Pascarella, E. T., \& Terenzini, P. T. (1991). How College Affects Students: Findings and Insights from Twenty Years of Research. San Francisco: Jossey-Bass.

Tam, M. (2004). Using students' self-reported gains as a measure of value-added. Quality in Higher Education, 10(3), 253-260. http://dx.doi.org/10.1080/1353832042000299531 
Uzuntiryaki, E. (2007). Learning Styles and High School Students Chemistry Achievement, Science Education international, 18(1), $25-37$.

Van Evera, W. C. (2007). Achievement and motivation in the middle school science classroom: The effects of formative assessment feedback. Doctoral Dissertation, George Maason University.

Yalcin, F. A., \& Bayrakceken, S. (2010). The effect of 5E learning model on pre-service teachers' achievement of acids-bases subject. International Online Journal of Educational Sciences, 2(2), 508-531.

\section{Copyrights}

Copyright for this article is retained by the author(s), with first publication rights granted to the journal.

This is an open-access article distributed under the terms and conditions of the Creative Commons Attribution license (http://creativecommons.org/licenses/by/3.0/). 